\title{
Magnetic Resonance Cholangiopancreatography versus Endosonography in Diagnosing Biliary Ducts Obstruction
}

El-Sayed Gaber Abd-Elhamid Ammar', Gamal Mohammad Mohammad Soliman', Mokhtar Ragab Ramadan ${ }^{2}$, Mahmoud Ismail Bastawy ${ }^{3}$, Mahmoud Mohammad Ghoname $^{{ }^{*}}$ 1-Tropical Medicine Department, 2-Radiology Department, 3-Clinical Pathology Department, Faculty of Medicine-Al Azhar University.

*Corresponding Author: Mahmoud Mohammad Ghoname, Tel: +201003802445, Email:ghonamemahmod@gmail.com

\begin{abstract}
Background: biliary obstruction or cholestasis is a common medical or surgical problem. Broadly speaking, the causes can be divided into intrahepatic and extrahepatic. The diagnosis of biliary tree can be done by different imaging modalities starting from transabdominal ultrasonography, to magnetic resonance cholangeopancreatograpy (MRCP) to endoscopic ultrasonography (EUS) and endoscopic cholangeopancreatography (ERCP) for diagnosis and treatment. Aim of the present work: this study aimed to evaluate the accuracy of these different modalities when compared to ERCP as diagnostic methods for diagnosis of different biliary tree abnormalities.

Patients and methods: eighty-four patients with obstructive jaundice were included and categorized into two groups group I: 56 patients with calcular obstructive jaundice, group II: 28 patients with non-calcular obstruction. Patients underwent history taking, clinical examination and routine laboratory investigations as well as tumor markers. Patients were examined by US, MRCP, EUS, ERCP and the findings of each modality were compared to ERCP. Results: the sensitivity and specificity of US in diagnosis of intrahepatic biliary dilatation (IHBRD) and common bile duct (CBD) dilatation were $81 \%, 100 \%$ and $33 \%$ and $100 \%$ for diagnosis of pancreatic tumors respectively. The sensitivity and specificity of MRCP in diagnosis of IHBRD was $97 \%$ and $100 \%$ successively and for CBD dilatation 79\% and 100\% successively and for diagnosis of pancreatic tumors $100 \%$ and $96 \%$ successively. The sensitivity and specificity of EUS in diagnosis of IHBRD were $100 \%$ and $100 \%$ successively and for CBD dilatation were $100 \%$ and $100 \%$ successively but in diagnosis of pancreatic tumors were $100 \%$ and $94 \%$ successively.

Conclusion: Both MRCP and EUS were good diagnostic modalities for biliary obstruction and pancreatic tumors with sensitivity and specificity of $>90 \%$ when compared to ERCP.
\end{abstract}

Keywords: biliary obstruction, jaundice, MRCP, ERCP, EUS

\section{INTRODUCTION}

Jaundice is yellowish discoloration of skin and mucous membranes due elevation of serum bilirubin. One of the causes of jaundice is obstruction of the lumen of the biliary tree which is the way of excretion of bilirubin after conjugation either due to something impacted within the lumen like stone (choledocolithiasis), parasites like fasciola or tumors fungating inside the lumen (cholangiocarcinoma) ${ }^{(\mathbf{1})}$. The obstruction of the biliary tree can be caused also by something in the wall of the biliary vessels like strictures due to injuries or accidental ligation during cholecystectomy, malignancy invading the wall or congenital anomalies of the biliary tree ${ }^{(2)}$.The obstruction can also be due to some mass compressing the ducts from outside like pancreatic tumors, portahepatis lymph nodes, duodenal carcinoma or severe spasm in the sphincter of Oddi ${ }^{(3)}$ .Abdominal US is usually the initial imaging test in jaundiced patients with suspected hepatobiliary disease. US can also demonstrate cholelithiasis and intrahepatic lesions more than $1 \mathrm{~cm}$ in diameter. US have the advantages of being noninvasive, portable and less expensive than other imaging studies. Disadvantages include dependence on the skill of the operator for the procedure and potential technical difficulty in obese patients or patients with excessive bowel gas that overlies some organs like the pancreas $^{(4)}$. MRCP techniques have greatly evolved and providing high radiology. Section resolution images of the biliary tree with short exam duration. The major disadvantages of MRCP compared with ERCP are lower resolution, unit availability, lack of any immediate therapy for duct obstruction, claustrophobia, and the inability to evaluate patients with pacemakers or ferromagnetic implants \& It is more expensive than US or $\mathrm{CT}^{(5)}$.

EUS can detect obstruction of the bile duct and major intrahepatic bile ducts. EUS has the potential advantage of permitting biopsy of suspected malignant lesions, and under appropriate circumstances, the operator can proceed directly to ERCP for definitive biliary decompression ${ }^{(6)}$.ERCP permits direct visualization of the biliary tract. ERCP is more invasive than US, CT, and MRCP and comparable in cost to $\mathrm{MRCP}^{(7)}$.After endoscopic 
identification of the ampulla of Vater, insertion of a catheter permits contrast injection into the biliary tract; sedation and analgesia are necessary. ERCP is highly accurate in diagnosis of biliary obstruction. If a focal cause of biliary obstruction (choledocholithiasis, biliary stricture) is identified, maneuvers to relieve obstruction (sphincterotomy, stone extraction, stricture dilation, stent placement) can be performed during the same session. Similarly, if there is concern about a neoplasm, biopsy and brushings for cytology can be performed. The technical success rate of diagnostic ERCP is higher than $90 \%$; the technique fails when the ampulla of Vater cannot be cannulated, as may be the case in patients with prior abdominal surgery and altered anatomy (gastric bypass, choledochojejunostomy ${ }^{\left({ }^{8}\right)}$.

The aim of this study is to evaluate the accuracy of different imaging modalities like MRCP and EUS is used in the diagnosis of biliary and pancreatic diseases in comparison with ERCP.

\section{PATIENTS AND METHODS}

This study was performed in Tropical Medicine Department at El-Hussein University Hospital during the period from June 2015 to January 2017. This study was carried on 84 patients with obstructive jaundice as proved by history, clinical examination and investigations included laboratory, US, MRCP, EUS and ERCP.

classified in to groups:

Group I: 56 patients proved to have calcular obstructive jaundice by imaging and endoscopy results.

Group II: 28 patients proved to have non-calcular obstructive jaundice by imaging and endoscopy results

\section{Inclusion criteria:}

Randomly selected patients with obstructive jaundice at Tropical Medicine Department, ElHussein University Hospital, between beginning of June 2015 and January 2017 were included in this study.

\section{Exclusion criteria:}

- Patients who didn't give clear consent to participate

- Patients presented with intrahepatic cholestasis.

- Patients with contraindications to Magnetic Resonance Cholangiopancreatography.

- Patients with contraindications to Endoscopic retrograde Cholangiopancreatography.

- Patients with past history of failed ERCP because of obvious technical obstacles.
- Patients with altered anatomy, identified during upper GIT series that are prohibiting Endoscopic retrograde Cholangiopancreatography.

- Patients with contraindications to sedation or general anesthesia.

All the patients were subjected to the following:

Full medical history: with special stress on risk factors: Age, gender, family history, smoking, obesity, metabolic diseases, abdominal surgery and other risk factors

Thorough clinical examination with special regard to Jaundice, Abdominal pain and/or tenderness or discomfort, change in color of urine or stool, history of gallstones, weight loss and anorexia, general constitutionals symptoms as fever, malaise, headache.. etc., ecchymosis and scratch marks abdominal masses.

The following laboratory investigations including

- Complete blood picture, Erythrocyte Sedimentation Rate (ESR).

- Liver function tests: aspartate aminotransferase (AST), alanine aminotransferase (ALT), total and direct serum bilirubin, total protein, serum albumin, alkaline phosphatase (ALP) and gamaglutamyltranspeptidase (GGT).

- Coagulation profile: prothrombin time (PT), and international normalized ratio (INR) by standard lab tests

- Renal Function Tests: serum creatinine.

- Tumor markers including CA19-9, AFP, CEA.

- HCV antibody

Abdominal and Pelvic ultrasonography during fasting was used to evaluate the following:

- Liver size, echo pattern and presence or absence of focal lesions.

- Presence of intrahepatic biliary radicles dilatation.

- Common bile duc $\mathrm{t}$ dilatation with or without stones.

- Pancreas for ( size, masses ,cyst or edema)

- Abdominal lymph node enlargement (Para aortic \&portahepatis).

Magnetic

Resonance

Cholangiopancreatography (MRCP):

MRCP was performed after a period of overnight fast 
by MR scanner 1.5 TESLA SIGNA DX Philips using eight channel body coil. 2D and 3D breathhold MRCP acquisition using sequences fast reversal fast spin echo (FRFSE) and steady state fast spin echo (SSFSE). Additionally T2 weighted fast spin echo (T2 FSE) or fat-saturated (FATSAT) sequences were performed to locate the dilated biliary and pancreatic ducts.

Magnetic
Cholangiopancreatography was used to
investigate suspected choledocholithiasis,
neoplastic obstruction (tumours), benign and
malignant strictures, chronic pancreatitis,
primary sclerosing cholangitis, anatomical
variants and postcholecystectomy biliary
disorders

Endosonography (EUS) EUS examination was carried out utilizing the forward oblique viewing linear Pentax video machine EG-3830 UT connected to a Hitachi sonography machine EUB-7000 (Tokyo, Japan). EUS was done under sedation and with patient in the right lateral position was used to evaluate the following:-

- Presence of intrahepatic biliary radicles dilatation.

- Common bile duct dilatation with or without stones.

- Gallbladder lesions

- Pancreas for ( size, masses ,cyst or edema)

- Hepatic focal lesions.

- Abdominal lymph node enlargement (Para aortic \&porta hepatis).

- Gastrointestinal masses.

Endoscopic

\section{Cholangiopancreatography}

used as a gold standard following:
- $\quad$ Presence of intrahepatic biliary radicles dilatation.

- Common bile duct dilatation with or without stones.
- Gallbladder lesions

- Pancreas for ( size, masses, ,cyst or edema)

- Hepatic focal lesions

- Abdominal lymph node enlargement (Para aortic \&porta hepatis).

- Gastrointestinal masses.

- Besides being a diagnostic modality, Endoscopic retrograde Cholangiopancreatography has a therapeutic application.

\section{Statistical Methods}

The statistical analysis was done using SPSS epi info version. Numerical data were represented as mean and slandered deviation while number and percentage were used to represent categorical variants. For comparison we used t test for numerical data and chisquare for categorical data. The cross tabulation was done to measure the diagnostic accuracy of various imaging modalities in comparison to ERCP as a gold standard.

\section{RESULTS}

Figure 1 showed that there were no significant differences between the studied groups as regards age, gender distribution, smoking and abdominal surgery. The last two being common risk factors for biliary and pancreatic diseases. Table 1 represented most of the clinical presenting signs and symptoms of biliary and pancreatic diseases and it showed that pain was significantly more frequent in calcular disease, while rate of anorexia and weight loss were significantly higher in non-calcular diseases. Comparing the two groups as regards their laboratory investigations we noticed that group II had significantly higher ESR and PT values, this group also had significantly higher level of the tumor markers carcinoemberyonic antigen and CA19-9 as shown in figures 2 and 3. 


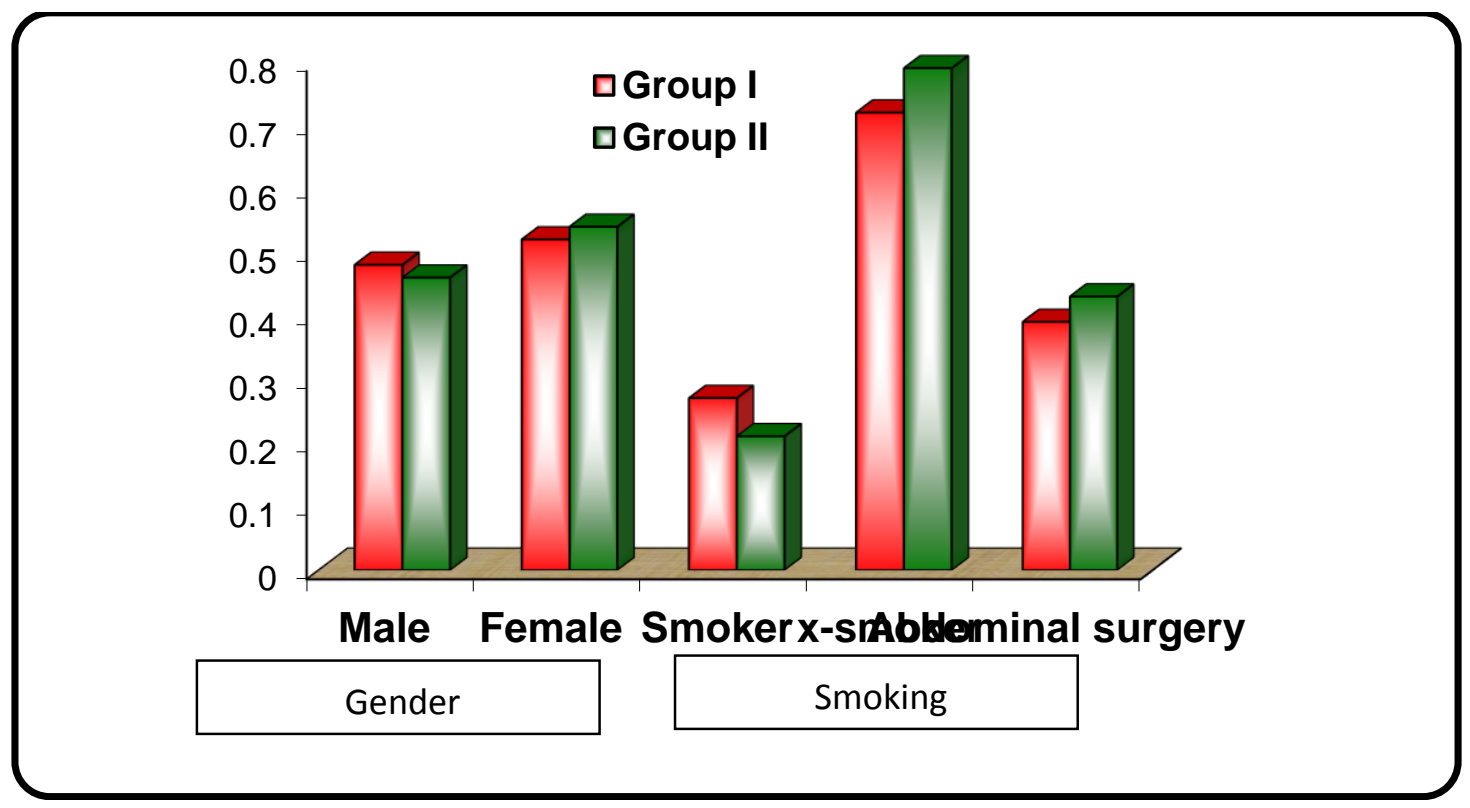

Figure 1: demographic data and risk factors

Table 1: comparison between the studied groups as regards clinical presentation (Symptoms and signs)

\begin{tabular}{|c|c|c|c|c|c|c|c|}
\hline & \multicolumn{2}{|c|}{$\begin{array}{l}\text { Group(I) } \\
\text { n(56) }\end{array}$} & \multicolumn{2}{|c|}{$\begin{array}{l}\text { Group(II) } \\
\text { n(28) }\end{array}$} & \multicolumn{2}{|l|}{$\mathrm{X}^{2}$} \\
\hline & & $\mathbf{N}$ & $\%$ & $\mathbf{N}$ & $\%$ & $\mathbf{P}$ & Signif. \\
\hline \multirow[t]{2}{*}{ Pain duration } & Acute & 11 & $20 \%$ & 1 & $4 \%$ & \multirow[t]{2}{*}{.054} & \multirow[t]{2}{*}{ NS } \\
\hline & Chronic & 45 & $80 \%$ & 27 & $96 \%$ & & \\
\hline \multirow[t]{3}{*}{ Pain nature } & Heaviness & 10 & $18 \%$ & 17 & $60 \%$ & \multirow[t]{3}{*}{.147} & \multirow[t]{3}{*}{ HS } \\
\hline & Colicky & 44 & $78 \%$ & 8 & $29 \%$ & & \\
\hline & Dull & 2 & $4 \%$ & 3 & $11 \%$ & & \\
\hline \multirow[t]{2}{*}{ Pain site } & Central & 16 & $29 \%$ & 13 & $46 \%$ & \multirow[t]{2}{*}{.144} & \multirow[t]{2}{*}{ NS } \\
\hline & rt.upper & 40 & $71 \%$ & 15 & $54 \%$ & & \\
\hline \multicolumn{2}{|l|}{ Pruritis } & 26 & $46 \%$ & 16 & $57 \%$ & .488 & NS \\
\hline \multicolumn{2}{|l|}{ Bleeding tendency } & 2 & $4 \%$ & 3 & $11 \%$ & .327 & NS \\
\hline \multicolumn{2}{|l|}{ Dark urine } & 39 & $70 \%$ & 20 & $71 \%$ & 1.000 & NS \\
\hline \multicolumn{2}{|l|}{ Pale stool } & 27 & $48 \%$ & 16 & $57 \%$ & .493 & NS \\
\hline \multicolumn{2}{|l|}{ Anorexia } & 11 & $20 \%$ & 20 & $71 \%$ & .000 & HS \\
\hline \multicolumn{2}{|l|}{ Weight loss } & 6 & $11 \%$ & 15 & $54 \%$ & .000 & HS \\
\hline \multirow[t]{5}{*}{ Upper.GI.symptoms } & No & 44 & $78 \%$ & 26 & $92 \%$ & \multirow[t]{5}{*}{.060} & \multirow[t]{5}{*}{ NS } \\
\hline & heartburn & 1 & $2 \%$ & 1 & $4 \%$ & & \\
\hline & vomiting & 7 & $13 \%$ & 0 & $0 \%$ & & \\
\hline & dyspepsia & 1 & $2 \%$ & 1 & $4 \%$ & & \\
\hline & Nausea & 3 & $5 \%$ & 0 & $0 \%$ & & \\
\hline \multicolumn{2}{|l|}{ Abdominal distention } & 2 & $4 \%$ & 1 & $4 \%$ & 1 & NS \\
\hline \multicolumn{2}{|l|}{ Scratch marks } & 25 & $45 \%$ & 15 & $54 \%$ & 0.49 & NS \\
\hline \multicolumn{2}{|l|}{ Palpable organs } & 0 & $0 \%$ & 1 & $4 \%$ & 0.333 & NS \\
\hline
\end{tabular}

Figures: 2,3: comparison between the two groups as regards the laboratory data 
El-Sayed Ammar et al.

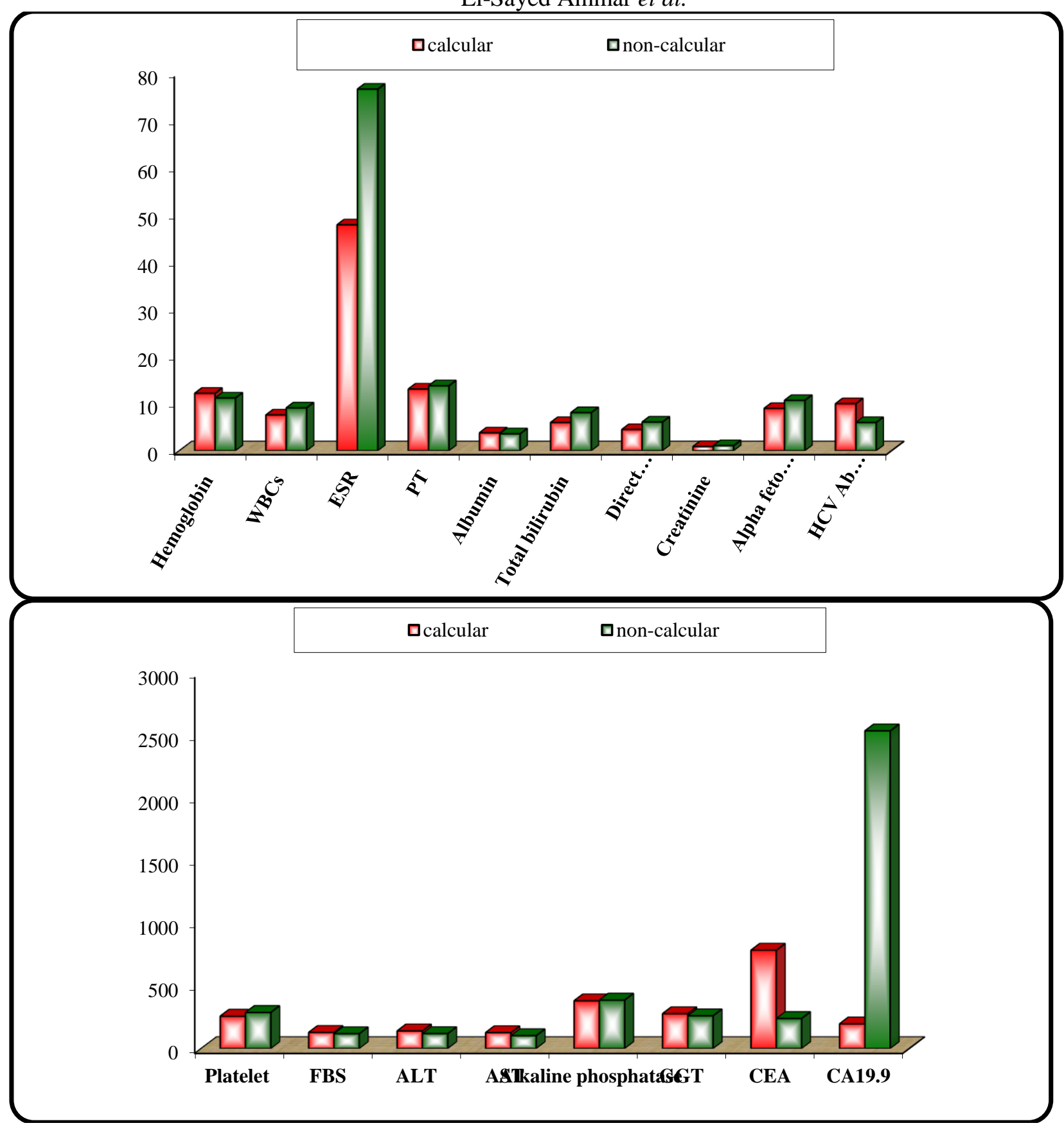

Figures: 2,3: comparison between the two groups as regards the laboratory data

Table 2 represented the different findings seen in both groups by using both ultrasonography and endosonography. As shown in table 2 it was clear that group I had significantly higher rate of stones seen by both modalities. Also it showed that group II had significantly higher rates of focal lesions and pancreatic masses than group I as detected by both modalities. No significant differences were seen as regards intrahepatic biliary radicles dilatation and common bile duct diameter as measured by both imaging modalities. Patients of group I had higher rate of gall bladder stones as seen in both imaging modalities. The same results seem to be similar to those found by ERCP and MRCP as shown in table 3. Comparison of ultrasonography, MRCP and EUS to ERCP as the gold standard for diagnosis showed that the performance of each modality was unique when compared to ERCP. Ultrasound was nearly as sensitive as ERCP in detection of common bile duct diameter and common bile duct abnormalities in noncalcular lesions. As shown in table 4 the MRCP was as sensitive as ERCP only in detection of common bile duct diameter in both groups. The EUS was comparable to ERCP in determination of common 
Magnetic Resonance Cholangiopancreatography ...

bile duct diameter as well as focal lesions in group I. the clinical performance as diagnostic modalities when compared to ERCP was represented in table 5. The sensitivity and specificity of US in diagnosis of intrahepatic biliary dilatation (IHBRD) and common bile duct (CBD) was $81 \%$ and $100 \%$ successively and for diagnosis of pancreatic tumors was $33 \%$ and $100 \%$ successively. The sensitivity and specificity of MRCP in diagnosis of intrahepatic biliary dilatation

Table 2: comparison between the studied groups as regards ultrasound and endosonography examination

\begin{tabular}{|c|c|c|c|c|c|c|c|}
\hline & & \multicolumn{3}{|c|}{ Ultrasonography } & \multicolumn{3}{|c|}{ Endosonography } \\
\hline & & $\begin{array}{l}\text { Group I } \\
\text { N (56) }\end{array}$ & $\begin{array}{l}\text { Group II } \\
\mathbf{N}(28)\end{array}$ & $\mathbf{P}$ & $\begin{array}{l}\text { Group I } \\
\mathbf{N}(56)\end{array}$ & $\begin{array}{l}\text { Group II } \\
\mathbf{N}(28)\end{array}$ & $\mathbf{P}$ \\
\hline & & $\mathbf{N}(\%)$ & $\mathrm{N}(\%)$ & & $\mathbf{N}(\%)$ & $\mathrm{N}(\%)$ & \\
\hline \multirow[t]{3}{*}{ IHBRD } & Bilobar & $43(77 \%)$ & $24(86 \%)$ & \multirow[t]{3}{*}{$.3(\mathrm{NS})$} & $43(77 \%)$ & $23(82 \%)$ & \multirow[t]{3}{*}{$0.17(\mathrm{NS})$} \\
\hline & No & $12(21 \%)$ & $3(11 \%)$ & & $12(21 \%)$ & $4(14 \%)$ & \\
\hline & Central & $1(2 \%)$ & $1(4 \%)$ & & $2(4 \%)$ & $1(4 \%)$ & \\
\hline \multirow{7}{*}{$\begin{array}{l}\text { CBD } \\
\text { abnormality }\end{array}$} & Stones & $23(41 \%)$ & $2(7 \%)$ & \multirow{6}{*}{$\begin{array}{l}<0.001 \\
\text { (HS) }\end{array}$} & $53(95 \%)$ & $1(4 \%)$ & \multirow{7}{*}{$\begin{array}{l}<0.001 \\
\text { (HS) }\end{array}$} \\
\hline & Stent & $3(5 \%)$ & $0(0 \%)$ & & $3(5 \%)$ & $1(4 \%)$ & \\
\hline & Normal & $29(52 \%)$ & $25(89 \%)$ & & $0(0 \%)$ & $2(7 \%)$ & \\
\hline & Stricture & $0(0 \%)$ & $0(0 \%)$ & & $0(0 \%)$ & $21(74 \%)$ & \\
\hline & Mass & $0(0 \%)$ & $1(4 \%)$ & & $0(0 \%)$ & $2(7 \%)$ & \\
\hline & Mud & $1(2 \%)$ & $0(0 \%)$ & & $0(0 \%)$ & $0(0 \%)$ & \\
\hline & Fasciola & $0(0 \%)$ & $0(0 \%)$ & & $0(0 \%)$ & $1(4 \%)$ & \\
\hline \multicolumn{2}{|c|}{ CBD diameter(mm) } & $10.3 \pm 3.9$ & $10.9 \pm 4.3$ & $0.3(\mathrm{NS})$ & $12.5 \pm 3.5$ & $12 \pm 4$ & $0.2(\mathrm{NS})$ \\
\hline \multicolumn{2}{|c|}{ GB wall thickening } & $20(36 \%)$ & $3(11 \%)$ & $0.4(\mathrm{NS})$ & $20(36 \%)$ & $3(11 \%)$ & $0.4(\mathrm{NS})$ \\
\hline \multirow{4}{*}{$\begin{array}{l}\text { Gall bladder } \\
\text { stones }\end{array}$} & Multiple & $30(53 \%)$ & $5(18 \%)$ & \multirow{4}{*}{$\begin{array}{l}0.008 \\
(\mathrm{~S})\end{array}$} & $31(55 \%)$ & $5(18 \%)$ & \multirow{4}{*}{$\begin{array}{l}<0.05 \\
(\mathrm{~S})\end{array}$} \\
\hline & Single & $2(4 \%)$ & $2(7 \%)$ & & $4(7 \%)$ & $2(7 \%)$ & \\
\hline & Mud & $4(7 \%)$ & $3(11 \%)$ & & $5(9 \%)$ & $5(18 \%)$ & \\
\hline & No & $5(9 \%)$ & $11(39 \%)$ & & $1(2 \%)$ & $12(43 \%)$ & \\
\hline \multicolumn{2}{|c|}{$\begin{array}{l}\text { Pancreas mass, edema, } \\
\text { dilated pancreatic duct }\end{array}$} & $0(0 \%)$ & $2(7 \%)$ & $\begin{array}{l}<0.001 \\
(\mathrm{HS})\end{array}$ & $0(0 \%)$ & $10(35 \%)$ & $\begin{array}{l}0.001 \\
(\mathrm{HS})\end{array}$ \\
\hline \multicolumn{2}{|c|}{ Porta hepatis LN } & $0(0 \%)$ & $1(4 \%)$ & $.004(\mathrm{~S})$ & $1(2 \%)$ & $7(25 \%)$ & $.001(\mathrm{HS})$ \\
\hline \multicolumn{2}{|l|}{ Focal leision } & $0(0 \%)$ & $2(7 \%)$ & $\begin{array}{l}0.001 \\
(\mathrm{HS})\end{array}$ & $1(2 \%)$ & $7(25 \%)$ & $\begin{array}{l}0.001 \\
(\mathrm{HS})\end{array}$ \\
\hline
\end{tabular}

Table 3: comparison between the two groups as regards findings of MRCP and ERCP

\begin{tabular}{|c|c|c|c|c|c|c|c|}
\hline & \multicolumn{3}{|l|}{ MRCP } & \multicolumn{3}{|l|}{ ERCP } \\
\hline & & $\begin{array}{l}\text { Group I } \\
\mathbf{N}(56)\end{array}$ & $\begin{array}{l}\text { Group II } \\
\mathbf{N}(28)\end{array}$ & \multirow[t]{2}{*}{$\mathbf{P}$} & $\begin{array}{l}\text { Group I } \\
\mathbf{N}(56)\end{array}$ & $\begin{array}{l}\text { Group II } \\
\mathbf{N}(28)\end{array}$ & \multirow[t]{2}{*}{$\mathbf{P}$} \\
\hline & & $\mathrm{N}(\%)$ & $\mathbf{N}(\%)$ & & $\mathbf{N}(\%)$ & $\mathrm{N}(\%)$ & \\
\hline \multirow[t]{3}{*}{ IHBRD } & Bilobar & $51(91 \%)$ & $23(82 \%)$ & \multirow{3}{*}{$\begin{array}{l}0.02 \\
(\mathrm{~S})\end{array}$} & $55(98 \%)$ & $28(100 \%)$ & \multirow{3}{*}{$\begin{array}{l}0.15 \\
(\mathrm{NS})\end{array}$} \\
\hline & No & $1(2 \%)$ & $1(4 \%)$ & & $0(0 \%)$ & $0(0 \%)$ & \\
\hline & Central & $4(7 \%)$ & $4(14 \%)$ & & $1(2 \%)$ & $0(0 \%)$ & \\
\hline \multirow{6}{*}{$\begin{array}{l}\text { CBD } \\
\text { abnormality }\end{array}$} & Stones & $48(85 \%)$ & $1(4 \%)$ & \multirow{6}{*}{$\begin{array}{l}<0.001 \\
\text { (HS) }\end{array}$} & $53(95 \%)$ & $0(0 \%)$ & \multirow{6}{*}{$\begin{array}{l}<0.001 \\
\text { (HS) }\end{array}$} \\
\hline & Stent & $3(5 \%)$ & $1(4 \%)$ & & $3(5 \%)$ & $0(0 \%)$ & \\
\hline & Normal & $4(7 \%)$ & $12(43 \%)$ & & $0(0 \%)$ & $1(4 \%)$ & \\
\hline & Stricture & $1(2 \%)$ & $12(43 \%)$ & & $0(0 \%)$ & $25(92 \%)$ & \\
\hline & Mass & $0(0 \%)$ & $0(0 \%)$ & & $0(0 \%)$ & $1(4 \%)$ & \\
\hline & Mud & $0(0 \%)$ & $0(0 \%)$ & & $0(0 \%)$ & $0(0 \%)$ & \\
\hline
\end{tabular}


El-Sayed Ammar et al.

\begin{tabular}{|c|c|c|c|c|c|c|}
\hline \multirow{2}{*}{\begin{tabular}{l|l} 
& Fasciola \\
CBD diameter(mm)
\end{tabular}} & $0(0 \%)$ & $0(0 \%)$ & & $0(0 \%)$ & $1(4 \%)$ & \\
\hline & $11.6 \pm 3.3$ & $11.8 \pm 4$ & $0.2(\mathrm{NS})$ & $12.6 \pm 3.2$ & $12.5 \pm 4.1$ & $0.07(\mathrm{NS})$ \\
\hline $\begin{array}{l}\text { Pancreas mass, edema, } \\
\text { dilated pancreatic duct }\end{array}$ & $0(0 \%)$ & $9(33 \%)$ & $\begin{array}{l}<0.001 \\
(\mathrm{HS})\end{array}$ & $0(0 \%)$ & $6(21 \%)$ & $\begin{array}{l}<0.001 \\
(\mathrm{HS})\end{array}$ \\
\hline Porta hepatis LN & $0(0 \%)$ & $2(7 \%)$ & $.001(\mathrm{HS})$ & & & \\
\hline Focal leision & $2(4 \%)$ & $3(11 \%)$ & $.02(\mathrm{~S})$ & $1(2 \%)$ & $1(4 \%)$ & $0.3(\mathrm{NS})$ \\
\hline
\end{tabular}

Table 4: comparison between ERCP and different other imaging modalities in the diagnosis of common biliary problems

\begin{tabular}{|l|l|l|l|l|l|}
\hline \multicolumn{2}{|c|}{} & \multicolumn{2}{l}{$\begin{array}{l}\text { Group(I) } \\
\mathbf{n}(\mathbf{5 6})\end{array}$} & \multicolumn{2}{l|}{$\begin{array}{l}\text { Group(II) } \\
\text { n(28) }\end{array}$} \\
\cline { 3 - 6 } \multicolumn{2}{|c|}{} & $\mathbf{P}$ & Signi. & $\mathbf{P}$ & Signi. \\
\hline \multirow{5}{*}{ ERCP to Ultrasound } & IHBRD & .000 & HS & .000 & HS \\
\cline { 2 - 6 } & CBD.diameter & .605 & NS & .944 & NS \\
\cline { 2 - 6 } & CBD.abnormality & .000 & HS & .688 & NS \\
\cline { 2 - 6 } & Pancreas & .004 & S & .000 & HS \\
\hline \multirow{5}{*}{ ERCP to endosonography } & IHBRD & .000 & HS & .000 & HS \\
\cline { 2 - 6 } & Focal leision & .041 & S & .000 & HS \\
\cline { 2 - 6 } & CBD.diameter & .903 & NS & .813 & NS \\
\cline { 2 - 6 } & CBD.abnormality & .000 & HS & .006 & S \\
\cline { 2 - 6 } & Pancreas & .004 & S & .008 & S \\
\hline ERCP to MRCP & IHBRD & .002 & S & .000 & HS \\
\cline { 2 - 6 } & Focal leision & .245 & NS & .037 & S \\
\cline { 2 - 6 } & CBD.diameter & .676 & NS & .545 & NS \\
\cline { 2 - 6 } & CBD.abnormality & .000 & HS & .000 & HS \\
\cline { 2 - 6 } & Pancreas & .004 & S & .049 & S \\
\hline
\end{tabular}

Table 5: sensitivity and specificity of different imaging modalities of imaging by cross tabulation against ERCP in detection of different biliary lesions

\begin{tabular}{|l|l|l|l|l|l|l|l|l|l|}
\hline & \multicolumn{4}{|l|}{ Ultrasounds } & \multicolumn{2}{l|}{ MRCP } & \multicolumn{2}{l|}{ EUS } \\
\cline { 2 - 10 } & CBD & IHBRD & $\begin{array}{l}\text { Pancreatic } \\
\text { mass }\end{array}$ & CBD & IHBRD & $\begin{array}{l}\text { Pancreatic } \\
\text { mass }\end{array}$ & CBD & IHBRD & $\begin{array}{l}\text { Pancreatic } \\
\text { mass }\end{array}$ \\
\hline Sensitivity & $\mathbf{8 1 . 9 \%}$ & $\mathbf{8 1 . 9 \%}$ & $\mathbf{3 3 . 3 \%}$ & $\mathbf{7 9 . 5 \%}$ & $\mathbf{9 7 . 6 \%}$ & $\mathbf{1 0 0 \%}$ & $\mathbf{1 0 0 \%}$ & $\mathbf{1 0 0 \%}$ & $\mathbf{1 0 0 \%}$ \\
\hline Specificity & $\mathbf{1 0 0 \%}$ & $\mathbf{1 0 0 \%}$ & $\mathbf{1 0 0 \%}$ & $\mathbf{1 0 0 \%}$ & $\mathbf{1 0 0 \%}$ & $\mathbf{9 6 . 2 \%}$ & $\mathbf{1 0 0 \%}$ & $\mathbf{1 0 0 \%}$ & $\mathbf{9 4 . 9 \%}$ \\
\hline
\end{tabular}

\section{DISCUSSION}

For patients with obstructive jaundice there is more than one imaging modality. The first one, easiest and most available of which is ultrasonography. For more non-invasive detailed examination of biliary tree the magnetic resonance cholangeopancreatography is a more accurate modality for imaging. The endosonography is a modality for imaging that is said to better visualize the pancreas and its tumors. Endoscopic cholangeopancreatography is a method not only for diagnosis but also for treatment of bile obstruction with extraction of stone and stenting of strictures in common bile duct. The use of all four modalities helped greatly in the diagnosis and management of biliary and pancreatic diseases $^{(4,5,6,8)}$.The aim of this study was to compare these different modalities in detection of different abnormalities in the biliary tree and measure their accuracy in comparison to the ERCP as the most accurate modality of imaging. The present study showed that there was no difference as regard gender between calcular and non calcular obstructive jaundice were more in males and this disagrees with results of Dabizzi $\boldsymbol{e t} \boldsymbol{a l}^{\left({ }^{(9)}\right.}$ who reported that pancreatic cancer has high incidence among males. The present study reported that abdominal pain was more common in calcular obstruction and anorexia, weight loss was more common in patients with non calcular cause of extra hepatic biliary obstruction (EHBO) and this agrees with results of Aijaz et al (10) $^{(1)}$ who stated that presence of dull or no pain, itching, anorexia, weight loss were common in patients with malignant cause of EHBO, while colicky abdominal pain and fever were more common in non-malignant 
Magnetic Resonance Cholangiopancreatography ...

cases of EHBO.Our study showed that serum CA199 was significantly elevated among most of the patients at the non calcular group and this agrees with results of Duraker $\boldsymbol{e t}$ al. ${ }^{(\mathbf{1 1})}$ who stated that despite a large number of putative biomarkers for pancreatic cancer, carbohydrate antigen (CA 19-9) was the goldstandard biomarker for pancreatic cancer diagnosis in symptomatic patients .Our study showed that the sensitivity of transabdominal ultrasound for detection of CBD abnormalities was $81.9 \%$ and this disagrees with results of Liu et al. (12) who reported that the sensitivity of transabdominal ultrasound for detection of CBD stones was only $26 \%$, but agrees with results of Shea et al. $^{(13)}$ and Verma et al.$^{(14)}$ who stated that transabdominal ultrasound was the initial screening modality of choice in cholelithiasis with a sensitivity and specificity of more than $80 \%$ the visualization of the bile duct by ultrasonography was operator dependent. Our study showed that the sensitivity of transabdominal ultrasound for detection of pancreatic abnormalities was $33.3 \%$ and this agrees with results of Yasuda et al. ${ }^{(15)}$ who said that sensitivity of transabdominal ultrasound for detection of smaller pancreatic masses less than $2-3 \mathrm{~cm}$ was $29 \%$ and disagrees with results of Conrad and FernándezDel ${ }^{(16)}$ who said that the US sensitivity for detecting pancreatic cancer is controversial and has been reported as anywhere between 50\%-90\%.Our study showed that sensitivity and specificity of MRCP in detection of CBD abnormality was $79.5 \%$ and $100 \%$ respectively and this agrees with results of Verma $\boldsymbol{e t}$ $\boldsymbol{a l}$.and Francesco et al.$^{(14,17)}$ who demonstrated the sensitivity and specifcity of $>90 \%$ on MRCP for detecting the benign etiology of obstruction.

Our study showed that the sensitivity and specificity of MRCP for detection of pancreatic abnormalities was $100 \%$ and $96.2 \%$ respectively and this agrees with results of Koelblinger et al. ${ }^{(18)}$ who stated that the mean sensitivity and specificity MR imaging for the detection of pancreatic cancer $95 \%$ and $96 \%$, respectively.Our study showed that the sensitivity and specificity of EUS for detection of CBD abnormalities was $98.8 \%$ and $100 \%$ respectively and this agrees with results of Sahai et al. $^{\left({ }^{(19)}\right.}$ who showed that sensitivity and specificity of EUS for detection of bile duct stones were $92 \%$ and $98 \%$ respectively. Thornton et al. (20) showed that endoscopic ultrasonography overcomes the limitation of evaluation of distal CBD by transabdominal sonography. It was very accurate in diagnosing CBD calculi with an overall accuracy of $96 \%$ as compared to $63 \%$ sensitivity of transabdominal sonography especially with small calculi or calculi with nondilated biliary system. Our study showed that the sensitivity and specificity of EUS for detection of pancreatic abnormalities was $100 \%$ and $94.9 \%$ respectively and this agrees with results of Yasuda $\boldsymbol{e t}$ al. ${ }^{(15)}$ who reported that EUS had a sensitivity of over $95 \%$ and was superior to several other imaging modalities including ERCP, MRI and helical CT for detecting pancreatic lesions $<2$ to $3 \mathrm{~cm}$. . And also agrees with results of Legmann et al. $^{(\mathbf{2 1 )}}$ who showed that EUS picks up small resectable pancreatobiliary mass with high sensitivity (93-100\%).

\section{CONCLUSION}

Both MRCP and EUS were good diagnostic modalities for biliary obstruction and pancreatic tumors with sensitivity and specificity of $>90 \%$ when compared to ERCP.

\section{REFERENCES}

1. Paul Dawson (2015): Bile Secretion and the enterohepatic circulation. Seisenger1 and Fordtrans's gastrointestinal and liver disease, $10^{\text {th }}$ edition copyright 2015 by Saunders, an imprint of Elsevier Inc.

2. Said K, Glaumann H, Bergquist A (2008): Gallbladder disease in patients with primary sclerosing cholangitis. J Hepatol ., 48:598-605.

3. American Cancer Society (2008): Cancer Facts and Figures 2008. Atlanta, American Cancer Society, 2008. From Basic Science to Clinical Practice, 3rd edn. Oxford: Blackwell.

4. Pedersen OM, Nordgard K, Kvinnsland S (1987): Value of sonography in obstructive jaundice. Limitations of bile duct caliber as an index of obstruction. Scand J Gastroenterol ., 22:975-81.

5. Vaishali MD, Agarwal AK, Upadhyaya DN et al (2004): MRI in obstructive jaundice. J Clin Gastroenterol ., 38:887-90.

6. Ainsworth AP, Rafaelsen SR, Wamberg PA et al. (2003): Is there a difference in diagnostic accuracy and clinical impact between EUS and MRCP? Endoscopy , 35:1029-32.

7. Griffin N, Wastle ML, Dunn WK et al. (2003): MRCP versus ERCP in the diagnosis of choledocholithiasis. Eur J Gastroenterol Hepatol ., 15: 9-13.

8. Talwalkar JA, Angulo P, Johnson CD et al. (2004): Cost-minimization analysis of MRC versus ERCP for the diagnosis of PSC and choledocholithiasis. Hepatology , 40:39-45.

9. Dabizzi E, Assef MS, Raimondo M et al. (2011): Diagnostic management of pancreatic cancer. Cancers;3 (1):494-509.

10. Aijaz A Sofi, Gul javid, Showkat Zargar et al. (2012): Comparative evaluation of ERCP and endosonography in the diagnosis of extrahepatic biliary obstruction and a suggested algorithm. Turk $\mathbf{J}$ Gastroenterol 2012; 23 (2): 135-140 
11. Duraker N, Hot S, Polat Y (2007): $C E A, C A 19-9$ and CA125 in the differetial diagnosis of begnin from malignant pancreatic disease with or without jaundice J.Surg Oncol., 95(2):142-147.

12. Liu CL, Lo CM, Chan JK et al. (2001): Detection of choledocholithiasis by EUS in acute pancreatitis: a prospective evaluation in 100 consecutive patients. Gastrointest Endosc., 54:325e30.

13. Shea JA, Berlin JA, Escarce JJ et al. (1994): Revised estimates of diagnostic test sensitivity and specificity in suspected biliary tract disease. Arch Intern Med.,154:2573-81.

14. Verma D, Kapadia A, Eisen GM et al. (2006): EUS vs MRCP for detection of choledocholithiasis. Gastrointest Endosc .,64:248-254.

15. Yasuda K, Mukai $H$ and Nakajima M (1995): Endoscopic ultrasonography diagnosis of pancreatic cancer. Gastrointest Endosc Clin N Am ., 5:699-712.

16. Conrad C, Fernández-Del Castillo C (2013): Preoperative evaluation and management of the pancreatic head mass. J Surg Oncol ., 107: 23-32

17. Francesco SF, Federica Fantozzi, Laura Tasciotti et al. (2005): A comparative study in 131 patients with suspected biliary obstruction. Med Sci Monit. , 11(3): 8-18.

18. Koelblinger $\mathrm{C}$, Ba-Ssalamah $\mathrm{A}$, Goetzinger $\mathrm{P}$ et al. (2011): Gadobenate dimeglumine-enhanced 3.0-T MR imaging versus multiphasic 64-detector row CT: prospective evaluation in patients suspected of having pancreatic cancer. Radiology, 259: 757-766

19. Sahai AV, Mauldin PD, Marsi V et al. (1999): Bile duct stones and laparoscopic cholecystectomy: A decision analysis to assess the roles of intraoperative cholangiography, EUS and ERCP. Gastrointest Endosc .,49:334-43.

20. Thornton JR, Lobo AJ, Lintott DJ et al. (1992): Value of ultrasound and liver function tests in determining the need for endoscopic retrograde cholangiopancreatography in unexplained abdominal pain. Gut , 33: 1559-61.

21. Legmann P, Vignaux O, Dousset B et al. (1998): Pancreatic tumors: comparison of dual-phase helical CT and edoscopic sonography. Am J Roentgenol ., 170: $1315-22$. 